TITLE:

\title{
Charge Transport in Intermixed Regions of All-Polymer Solar Cells Studied by Conductive Atomic Force Microscopy
}

\section{$\operatorname{AUTHOR}(S)$ :}

Osaka, Miki; Mori, Daisuke; Benten, Hiroaki; Ogawa, Hiroki; Ohkita, Hideo; Ito, Shinzaburo

\section{CITATION:}

Osaka, Miki ... [et al]. Charge Transport in Intermixed Regions of All-Polymer Solar Cells Studied by Conductive Atomic Force Microscopy. ACS Applied Materials \& Interfaces 2017, 9(18): 15615-15622

\section{ISSUE DATE:}

2017-05-10

URL:

http://hdl.handle.net/2433/226947

\section{RIGHT:}

This document is the Accepted Manuscript version of a Published Work that appeared in final form in 'ACS Applied Materials \& Interfaces', copyright $\odot$ American Chemical Society after peer review and technical editing by the publisher. To access the final edited and published work see http://doi.org/10.1021/acsami.7b00979.; The full-text file will be made open to the public on 24 April 2018 in accordance with publisher's 'Terms and Conditions for Self-Archiving'.; の論文は出版社版でありません。引用の際には出版社版をご確認じ利用ください。; This is not the published version. Please cite only the published version. 


\section{Charge Transport in Intermixed Regions of All-Polymer}

\section{Solar Cells Studied by Conductive Atomic Force}

\section{Microscopy}

Miki Osaka, ${ }^{1}$ Daisuke Mori, ${ }^{1}$ Hiroaki Benten, ${ }^{1,2^{*}}$ Hiroki Ogawa, ${ }^{3}$ Hideo Ohkita, ${ }^{1}$ and Shinzaburo Ito ${ }^{1}$

${ }^{1}$ Department of Polymer Chemistry, Graduate School of Engineering, Kyoto University, Katsura, Nishikyo, Kyoto 615-8510, JAPAN

${ }^{2}$ Graduate School of Materials Science, Nara Institute of Science and Technology, Takayama-cho, Ikoma, Nara 630-0192, JAPAN

${ }^{3}$ Institute for Chemical Research, Kyoto University, Uji 611-0011, JAPAN

Keywords: Conductive atomic force microscopy, Nanoscale current imaging, Poly(3hexylthiophene), Phase separation, Conjugated polymer blend, All polymer solar cell, Charge transport, Interface 


\section{ABSTRACT}

Charge transport in intermixed regions of all-polymer solar cells based on a blend of poly(3hexylthiophene) (P3HT; electron donor) with poly[2,7-(9,9-didodecylfluorene)-alt-5,5-(4',7'bis(2-thienyl)-2',1',3'-benzothiadiazole)] (PF12TBT; electron acceptor) was studied by conductive atomic force microscopy (C-AFM). For a blend film fabricated from a chlorobenzene solution, intermixed regions were detected between the P3HT-rich and PF12TBT-rich domains. The overall hole current in the intermixed regions remained almost constant, both before and after thermal annealing at $80{ }^{\circ} \mathrm{C}$, but it increased in the P3HT-rich domains. For a blend film fabricated from a chloroform solution, the entire observed area constituted an intermixed region, both before and after thermal annealing. The overall hole current in this film was significantly improved following thermal annealing at $120^{\circ} \mathrm{C}$. These finely mixed structures with efficient charge transport yielded a maximum power conversion efficiency of $3.5 \%$. The local charge transport properties in the intermixed region, as observed via C-AFM, was found to be closely related to the photovoltaic properties, rather than the bulkaveraged properties or topological features. 


\section{INTRODUCTION}

All-polymer solar cells based on blends of conjugated polymers acting as electron donors (hole transport) and acceptors (electron transport) have recently attracted considerable attention as alternatives to polymer/fullerene blend solar cells, because of the extensive scope for tuning the optical, electronic, morphological, and mechanical properties of the blend films. ${ }^{1-4}$ For efficient photovoltaic operation, it is critical that a photogenerated exciton reaches a donor/acceptor interface at which it can be dissociated to form charge carriers. This process is then followed by charge collection at the device electrodes through charge-transport networks in the donor and acceptor domains. Thus, the phase-separated structure of a blend film should be comparable to the exciton diffusion length, which is typically $10 \mathrm{~nm}^{5}$ Many efforts have been made to optimize the morphology of polymer-blend films using various trial and error method-based approaches: controlling the processing conditions, such as the choice of solvent and the thermal annealing steps; adjusting the polymer regioregularity and molecular weight; or adjusting the chemical structure of the polymer side chains. ${ }^{2-4}$ Consequently, the power conversion efficiencies (PCEs) of all-polymer solar cells have steadily improved in recent years. $^{2}$ However, clarification of the relationship between the blend-film morphology and device performance is of particular importance, and it is essential to rational design of highly efficient all-polymer solar cells.

Blends of donor and acceptor polymers inherently possess heterogeneous electrical properties at nanometer scale because of their complicated morphological features, ${ }^{6-10}$ and these heterogeneities significantly affect the device performance. Therefore, nanoscale characterization of the electrical properties of blend films provides critical information for understanding the effect of blend morphology on overall device performance. For instance, information on efficiencies of charge generation and bulk-averaged charge transport in a given 
film can be obtained separately from the measurements of photoluminescence (PL) quenching and the current-voltage $(J-V)$ properties, respectively. However, little is known about local charge transport at the intermixed region of donor and acceptor domains, which should have a critical impact on the photovoltaic properties because excitons are more efficiently converted to charge carriers in this region. Analysis via conductive atomic force microscopy (C-AFM) can offer insight into the charge generation and charge transport by providing a high-resolution and direct view of the local electrical properties of nanostructured materials such as conjugated polymer blends. ${ }^{11-15}$

Herein, we present our findings, obtained using C-AFM, on the relationship between the photovoltaic properties and local charge transport behavior of all-polymer solar cells composed of a semicrystalline electron donor, poly(3-hexylthiophene) (P3HT), and an amorphous electron acceptor, poly[2,7-(9,9-didodecylfluorene)-alt-5,5-(4',7'-bis(2-thienyl)-2', 1',3'benzothiadiazole)] (PF12TBT) on a poly(3,4-ethylenedioxythiophene):poly(4styrenesulfonate) (PEDOT:PSS) substrate. ${ }^{16}$ The phase-separated morphology and the effect of thermal annealing on the device performance were strongly dependent on the solvents employed for spin-coating, which had a critical impact on the best PCE. For a device of P3HT/PF12TBT blend fabricated by spin-coating from a chlorobenzene (CB) solution, largely phase-separated structures were found before and after thermal annealing, resulting in low photovoltaic performance. For a device of P3HT/PF12TBT blend fabricated by spin-coating from a chloroform (CF) solution, however, finely mixed structures were found throughout the entire the film both before and after thermal annealing. The photovoltaic performance was low before the thermal annealing, but it improved after this process. We will discuss the origin of the difference in the photovoltaic performance between these $\mathrm{CB}$ and $\mathrm{CF}$ devices in terms of the local charge transport in the phase-separated morphology visualized by C-AFM. 


\section{EXPERIMENTAL}
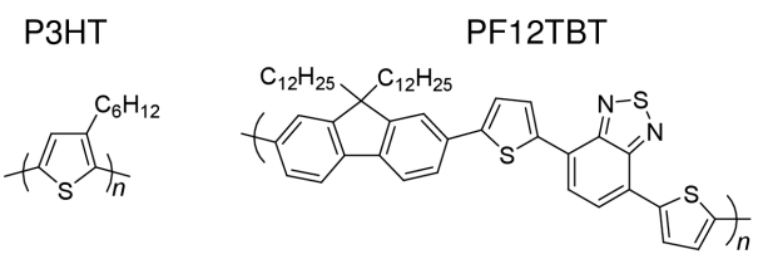

Figure 1. Chemical structures of (a) P3HT and (b) PF12TBT.

Materials. The donor polymer P3HT was purchased from Aldrich Chemical Co., USA (lot MKBD3325V). According to the certificate of analysis, the head-to-tail regioregularity, weight-average molecular weight $\left(M_{\mathrm{w}}\right)$, and polydispersity index (PDI, given by $M_{\mathrm{w}} / M_{\mathrm{n}}$, where $M_{\mathrm{n}}$ is the number-average molecular weight) were $90.0 \%, 42300 \mathrm{~g} \mathrm{~mol}^{-1}$, and 1.9 , respectively. The acceptor polymer, PF12TBT, was synthesized and characterized by Sumitomo Chemical Co., Ltd., Japan: the $M_{\mathrm{w}}$, and PDI were $26900 \mathrm{~g} \mathrm{~mol}^{-1}$ and 3.4, respectively. The chemical structures of P3HT and PF12TBT are shown in Figure 1. Poly(3,4ethylenedioxythiophene):poly(4-styrenesulfonate) (PEDOT:PSS, PH-500) was purchased from H. C. Starck, USA.

Sample Preparation. An indium-tin-oxide (ITO) (flat ITO, GEOMATEC, Japan) substrate, an $\operatorname{Si}(100)$ wafer (Yamanaka Hutech, Japan), and a quartz substrate were sequentially washed for 15 min by ultrasonication with toluene, acetone, and ethanol; the substrates were then dried under $\mathrm{N}_{2}$ flow. The cleaned substrates were further treated with an ultraviolet-ozone (UV$\mathrm{O}_{3}$ ) cleaner (NL-UV2535, Nippon Laser \& Electronics Lab., Japan) for 30 min. An 80-nmthick PEDOT:PSS layer was first spin-coated at $400 \mathrm{rpm}$ for $10 \mathrm{~s}$ and then at $3000 \mathrm{rpm}$ for 99 s onto the ITO substrate and the Si wafer and dried at $140{ }^{\circ} \mathrm{C}$ for $30 \mathrm{~min}$ in air. Next, a 
P3HT/PF12TBT film was spin-coated from a solution of the P3HT/PF12TBT blend onto the PEDOT:PSS|ITO, PEDOT:PSS|Si, and quartz substrate. Two different solvents—chloroform (CF) and chlorobenzene (CB) — were used to prepare the polymer-blend solutions. Each blend solution was prepared by mixing $\mathrm{P} 3 \mathrm{HT}$ and PF12TBT at a weight ratio of 1:1, i.e., $6.0 \mathrm{mg}$ of P3HT and $6.0 \mathrm{mg}$ of PF12TBT were dissolved in $1 \mathrm{~mL}$ of CF, and $7.5 \mathrm{mg}$ of P3HT and $7.5 \mathrm{mg}$ of PF12TBT were dissolved in $1 \mathrm{~mL}$ of $\mathrm{CB}$. For the $\mathrm{CF}$ solution of the P3HT/PF12TBT blend, the spin-coating was carried out at $3000 \mathrm{rpm}$ for $60 \mathrm{~s}$; for the $\mathrm{CB}$ solution of the P3HT/PF12TBT blend, the spin-coating was carried out at $1500 \mathrm{rpm}$ for $120 \mathrm{~s}$. Neat P3HT and PF12TBT films were prepared by spin-coating each CF solution onto the PEDOT:PSS|ITO, PEDOT:PSS|Si, and quartz substrate. The thickness of the resulting blend and neat films was measured using the AFM (SPM-9600, Shimadzu, Japan) in contact mode: a part of each film was scratched with a sharp needle to expose the substrate, and the film thickness was evaluated from the difference in height between the film and substrate surface. The thickness of the P3HT/PF12TBT blend and neat P3HT films was $\sim 65 \mathrm{~nm}$.

Macroscopic $\boldsymbol{J}-\boldsymbol{V}$ Measurements. The hole-only current density-voltage $(J-V)$ characteristics were measured for the neat P3HT film and P3HT/PF12TBT blend films sandwiched between the PEDOT:PSS|ITO substrate and a Au electrode. Each polymer layer was spin-coated onto the PEDOT:PSS|ITO substrate and then annealed at 80 or $120{ }^{\circ} \mathrm{C}$ for 10 min under a $\mathrm{N}_{2}$ atmosphere. Finally, the Au top electrode was vacuum-deposited at $3 \times 10^{-4}$ Pa on top of the film; the Au layer had a thickness of $70 \mathrm{~nm}$ and a surface area of $0.07 \mathrm{~cm}^{2}$. The $J-V$ characteristics were measured with a direct-current voltage and a current source/monitor (R6243, Advantest, Japan) in the dark at $21^{\circ} \mathrm{C}$. The conductivity $\sigma$ was calculated from the slope of the $J-V$ curve at lower voltages given by Ohm's law, $J_{\mathrm{OHM}}=\sigma V / L$, 
where $V$ is the applied voltage and $L$ is the sample thickness. The hole mobility $\mu_{\mathrm{h}}$ was determined by fitting the space-charge-limited current (SCLC) that appeared at higher voltages with the Mott-Gurney equation, $J_{\mathrm{SCL}}=(9 / 8) \varepsilon_{0} \varepsilon_{\mathrm{r}} \mu_{\mathrm{h}} V^{2} / L^{3}$, where $V$ is the applied voltage, $L$ is the sample thickness, $\varepsilon_{0}$ is the vacuum permittivity, and $\varepsilon_{\mathrm{r}}$ is the dielectric constant of the film (we assumed $\varepsilon_{\mathrm{r}}=3$ for P3HT). ${ }^{17}$

Solar Cell Fabrication and Characterization. The solar-cell characteristics were measured for each device of P3HT/PF12TBT blend fabricated as follows. The P3HT/PF12TBT blend films were spin-coated onto the PEDOT:PSS|ITO substrates; each film was then annealed at a different temperature $\left(60,80,100,120\right.$, or $\left.140^{\circ} \mathrm{C}\right)$ for 10 min under a $\mathrm{N}_{2}$ atmosphere. Finally, a calcium layer (thickness: $10 \mathrm{~nm}$ ) and an aluminum layer (thickness: $70 \mathrm{~nm}$ ) were sequentially vacuum-deposited at $2.5 \times 10^{-4} \mathrm{~Pa}$ through a shadow mask. The active area of each device was $0.07 \mathrm{~cm}^{2}$, which was defined as the area of the $\mathrm{Ca} / \mathrm{Al}$ electrode. The $J-V$ characteristics were measured with a direct-current voltage and a current source monitor (R6243, Advantest, Japan) under AM1.5G simulated solar illumination with a power density of $100 \mathrm{~mW} \mathrm{~cm} \mathrm{ct}^{-2}$ at $21^{\circ} \mathrm{C}$

Absorption Measurements. The UV-visible absorption spectra were measured for the neat PF12TBT film, neat P3HT film, and P3HT/PF12TBT blend films, which were spin-coated on quartz substrates and then annealed at a different temperature $\left(60,80,100,120\right.$, or $\left.140{ }^{\circ} \mathrm{C}\right)$ for 10 min under a $\mathrm{N}_{2}$ atmosphere, by using a spectrophotometer (U-3500, Hitachi, Japan).

Photoluminescence Quenching Measurements. PL spectra were measured for both the neat PF12TBT film and P3HT/PF12TBT blend films, which were spin-coated on quartz substrates 
and then annealed at a different temperature $\left(60,80,100,120\right.$, or $\left.140{ }^{\circ} \mathrm{C}\right)$ for 10 min under a $\mathrm{N}_{2}$ atmosphere, by using a calibrated fluorescence spectrophotometer (F-4500, Hitachi, Japan). The excitation wavelength was set at $392 \mathrm{~nm}$ in order to mainly excite the PF12TBT component (the excitation fraction of PF12TBT was 75\%, while that of P3HT was 25\%). The PL intensity was corrected for variations in the PF12TBT absorption at $392 \mathrm{~nm}$. The PL quenching efficiency $\left(\Phi_{\mathrm{q}}\right)$ of PF12TBT in the blend film was evaluated from the ratio of the PL intensity for the P3HT/PF12TBT blend films to that of the neat PF12TBT film.

C-AFM Measurements. The P3HT/PF12TBT blend films were prepared on PEDOT:PSS|ITO substrates and annealed separately at $80{ }^{\circ} \mathrm{C}$ or $120^{\circ} \mathrm{C}$ for 10 min under a $\mathrm{N}_{2}$ atmosphere. C-AFM measurements were performed using the microscope (SPM-9600, Shimadzu, Japan) in contact mode. In these measurements, Au-coated silicon probes (PPPCONTAu, NANOSENSORS, Switzerland; tip radius: <50 nm; spring constant: $0.2-0.25 \mathrm{~N}$ $\mathrm{m}^{-1}$ ) were used to ensure that holes were the major carriers of the current. ${ }^{14}$ A sample bias was applied to the ITO substrate, and the probe was grounded. The surface topography and corresponding current images were simultaneously obtained by the C-AFM operating at a constant sample bias of $+3.0 \mathrm{~V}$. All C-AFM measurements were performed under a $\mathrm{N}_{2}$ atmosphere in a controlled-environment chamber (CH-III, Shimadzu, Japan).

GIWAXS Measurements. Grazing-incidence wide-angle X-ray scattering (GIWAXS) measurements were carried out at $21{ }^{\circ} \mathrm{C}$ for the P3HT/PF12TBT blend and neat P3HT films using the BL03XU beamline of SPring-8 (Japan Synchrotron Radiation Research Institute, Hyogo, Japan). The wavelength $(\lambda)$ of the $X$-rays was set to $0.1 \mathrm{~nm}$, and the $\mathrm{X}$-ray beam was directed on the sample at an incident angle $\left(\alpha_{\mathrm{i}}\right)$ of $0.14^{\circ}$ with respect to the sample surface. 
The scattering signal was detected by a two-dimensional CCD camera with a $3000 \times 3000$ pixel imaging plate, which was located at a distance of $464 \mathrm{~mm}$ from the sample. The scattering intensity was recorded as a function of the two scattering angles: in-plane angle $\left(2 \theta_{\mathrm{f}}\right)$ with respect to the plane of incidence; and exit angle $\left(\alpha_{\mathrm{f}}\right)$ with respect to the sample surface. ${ }^{18}$ These angles are related to the scattering vector along the $q_{y}$ axis and the $q_{z}$ axis according to the following equations: $q_{y}=k_{0}\left[\sin \left(2 \theta_{\mathrm{f}}\right) \cos \left(\alpha_{\mathrm{f}}\right)\right] ; q_{z}=k_{0}\left[\sin \left(\alpha_{\mathrm{f}}\right)+\sin \left(\alpha_{\mathrm{i}}\right)\right] ; k_{0}=2 \pi / \lambda^{18} \quad$ The thermal annealing of the neat P3HT films for GIWAXS measurements was conducted separately at 100 or $120{ }^{\circ} \mathrm{C}$ for 10 min under a $\mathrm{N}_{2}$ atmosphere. The thermal annealing of the P3HT/PF12TBT blend film was conducted sequentially from 60 to $120{ }^{\circ} \mathrm{C}$ in increments of $20{ }^{\circ} \mathrm{C}$ steps for $10 \mathrm{~min}$ at each temperature. The GIWAXS measurements were conducted at $21{ }^{\circ} \mathrm{C}$ for the same P3HT/PF12TBT film after each round of annealing.

\section{RESULTS}

\section{Performance of P3HT/PF12TBT Solar Cells.}

Figure 2 shows the $J-V$ characteristics of solar cells of P3HT/PF12TBT blend fabricated by spin-coating from the $\mathrm{CB}$ and $\mathrm{CF}$ solutions (hereafter referred to as the $\mathrm{CB}$-blend device and CF-blend device). Thermal annealing at $80^{\circ} \mathrm{C}$ and $120^{\circ} \mathrm{C}$ provided the best $\mathrm{PCE}$ for the CBblend device and the CF-blend device, respectively (see Supporting Information, Figure S1). The broken and solid lines represent the $J-V$ curves before and after thermal annealing, respectively, at the optimized temperature for $10 \mathrm{~min}$. Before thermal annealing, both devices exhibited poor photovoltaic performance with a PCE of less than $1 \%$. This poor performance was primarily due to the small short-circuit current density $\left(J_{\mathrm{SC}}\right)$ and fill factor $(\mathrm{FF})$, which were independent of the spin-coating solvents. After optimization using thermal annealing, on the other hand, the PCE improved slightly from $0.9 \%$ to $1.2 \%$ for the CB-blend device while a 
dramatic PCE improvement from $0.59 \%$ to $3.5 \%$ was observed for the CF-blend device. As a result, the PCE of the CF-blend device was three times that of the CB-blend device. In the following sections, we will discuss this large difference between the two devices before and after thermal annealing in terms of the macroscopic conductive properties, P3HT crystallization evaluated from UV-vis absorption and GIWAXS analyses, microscopic phase-separated structures estimated from the PL quenching measurements, and the microscopic conductive properties measured by $\mathrm{C}-\mathrm{AFM}$.

(a)

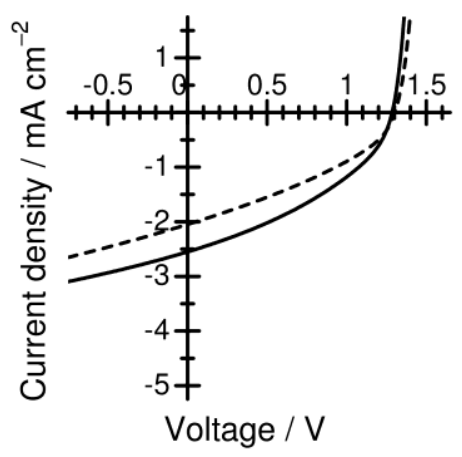

(b)

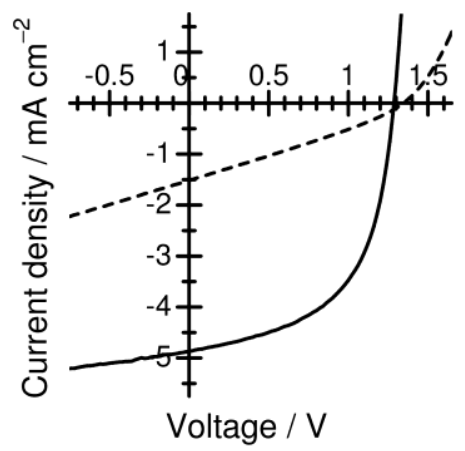

Figure 2. $J-V$ characteristics of P3HT/PF12TBT solar cells under AM 1.5G, $100 \mathrm{~mW} \mathrm{~cm} \mathrm{~cm}^{-2}$ illumination. These devices were fabricated by spin-coating from (a) CB and (b) CF solutions, and the $J-V$ characteristics were measured before (broken lines) and after optimization using thermal annealing for $10 \mathrm{~min}$ (solid lines). The device parameters are listed in Table 1. 
Table 1. Photovoltaic parameters of P3HT/PF12TBT solar cells.

\begin{tabular}{ccccc}
\hline Solvent / Annealing temperature & $\mathrm{PCE} / \%$ & $J_{\mathrm{SC}} / \mathrm{mA} \mathrm{cm}^{-2}$ & $\mathrm{FF}$ & $V_{\mathrm{OC}} / \mathrm{V}$ \\
\hline $\mathrm{CB} / \mathrm{As}$-cast & $0.91 \pm 0.05$ & $2.02 \pm 0.04$ & $0.35 \pm 0.02$ & $1.31 \pm 0.01$ \\
$\mathrm{CB} / 80{ }^{\circ} \mathrm{C}$ & $1.19 \pm 0.05$ & $2.38 \pm 0.13$ & $0.40 \pm 0.01$ & $1.27 \pm 0.01$ \\
$\mathrm{CF} / \mathrm{As}$-cast & $0.59 \pm 0.04$ & $1.52 \pm 0.12$ & $0.29 \pm 0.00$ & $1.35 \pm 0.01$ \\
$\mathrm{CF} / 120^{\circ} \mathrm{C}$ & $3.49 \pm 0.12$ & $4.87 \pm 0.13$ & $0.55 \pm 0.01$ & $1.29 \pm 0.00$
\end{tabular}

\section{Macroscopic Hole-Transport Properties of Blend Films.}

To examine the effect of the spin-coating solvent and subsequent thermal annealing on the macroscopic hole transport of the blend films, we evaluated the conductivity $(\sigma)$ and hole mobility $\left(\mu_{\mathrm{h}}\right)$ of the blend films by analyzing the hole-only $J-V$ characteristics. The value of $\sigma$ was calculated from the slope of the $J-V$ curve in the Ohmic region, and $\mu_{\mathrm{h}}$ was calculated from the $J-V$ curve in the SCLC region with the Mott-Gurney equation. For the blend film fabricated from the CB solution, $\sigma$ increased from $2.2 \times 10^{-8}$ to $4.0 \times 10^{-8} \mathrm{~S} \mathrm{~cm}^{-1}$ and $\mu_{\mathrm{h}}$ increased from $0.6 \times 10^{-4}$ to $1.2 \times 10^{-4} \mathrm{~cm}^{2} \mathrm{~V}^{-1} \mathrm{~s}^{-1}$ after thermal annealing. For the blend film fabricated from the CF solution, $\sigma$ increased from $1.7 \times 10^{-8}$ to $3.8 \times 10^{-8} \mathrm{~S} \mathrm{~cm}^{-1}$ and $\mu_{\mathrm{h}}$ increased from $0.2 \times 10^{-4}$ to $0.8 \times 10^{-4} \mathrm{~cm}^{2} \mathrm{~V}^{-1} \mathrm{~s}^{-1}$ after thermal annealing. In summary, the $\sigma$ and $\mu_{\mathrm{h}}$ values were higher for the CB-blend device than for the CF-blend device. For comparison, $\sigma$ and $\mu_{\mathrm{h}}$ were also measured for neat $\mathrm{P} 3 \mathrm{HT}$ films spin-coated from the CF solution and annealed at 80 and $120^{\circ} \mathrm{C}$. The $\sigma$ and $\mu_{\mathrm{h}}$ values are summarized in Table 2 . 
Table 2. Conductive and morphological properties of P3HT/PF12TBT blend and neat P3HT films.

\begin{tabular}{cccccc}
\hline Films & $\begin{array}{c}\text { Solvent / Annealing } \\
\text { temperature }\end{array}$ & $\sigma / 10^{-8} \mathrm{~S} \mathrm{~cm}^{-1}$ & $\mu_{\mathrm{h}} / 10^{-4} \mathrm{~cm}^{2} \mathrm{~V}^{-1} \mathrm{~s}^{-1}$ & $L_{\pi} / \mathrm{nm}$ & $\Phi_{\mathrm{q}} / \%$ \\
\hline Blend & $\mathrm{CB} /$ As-cast & $2.2 \pm 1.1$ & $0.6 \pm 0.1$ & 6.4 & $65 \pm 3.6$ \\
Blend & $\mathrm{CB} / 80^{\circ} \mathrm{C}$ & $4.0 \pm 2.5$ & $1.2 \pm 0.0$ & 7.0 & $61 \pm 2.9$ \\
Blend & $\mathrm{CF} /$ As-cast & $1.7 \pm 0.5$ & $0.2 \pm 0.0$ & 4.1 & 85 \\
Blend & $\mathrm{CF} / 120^{\circ} \mathrm{C}$ & $3.8 \pm 0.9$ & $0.8 \pm 0.0$ & 6.1 & 72 \\
P3HT & $\mathrm{CF} / 80^{\circ} \mathrm{C}$ & $2.5 \pm 1.3$ & $3.5 \pm 0.5$ & 6.7 & - \\
P3HT & $\mathrm{CF} / 120^{\circ} \mathrm{C}$ & $2.3 \pm 0.3$ & $4.2 \pm 0.4$ & 6.8 & -
\end{tabular}

\section{Morphology of P3HT in Blend Film.}

3-1. Absorption Spectra. Figures $3 \mathrm{a}$ and $3 \mathrm{~b}$ show the absorption spectra of P3HT/PF12TBT blend films spin-coated from the $\mathrm{CB}$ and $\mathrm{CF}$ solutions before and after the thermal annealing. Note that the spectral shape in the 500-650 $\mathrm{nm}$ wavelength range is a good measure of the degree of ordering of the P3HT polymer chains. ${ }^{19-21}$ In the spectra obtained before thermal annealing, the absorption shoulder in the vicinity of $600 \mathrm{~nm}$ is more pronounced for the blend film from $\mathrm{CB}$ than the blend film from $\mathrm{CF}$, suggesting that $\mathrm{P} 3 \mathrm{HT}$ chains were more ordered (or crystallized) in the CB-blend film. In the spectra obtained after thermal annealing, the shoulder is prominent for both blend films, suggesting growth of the ordering (or crystallization) of P3HT chains. In accordance with previous reports, ${ }^{22,23}$ the $\pi$-conjugation length $\left(L_{\pi}\right)$ of the P3HT chains was estimated for each blend film (see the Supporting Information, Figures S2 and S3). As summarized in Table 2, $L_{\pi}$ was larger for the CB-blend film than the CF-blend film, and it increased for both blend films after thermal annealing. 

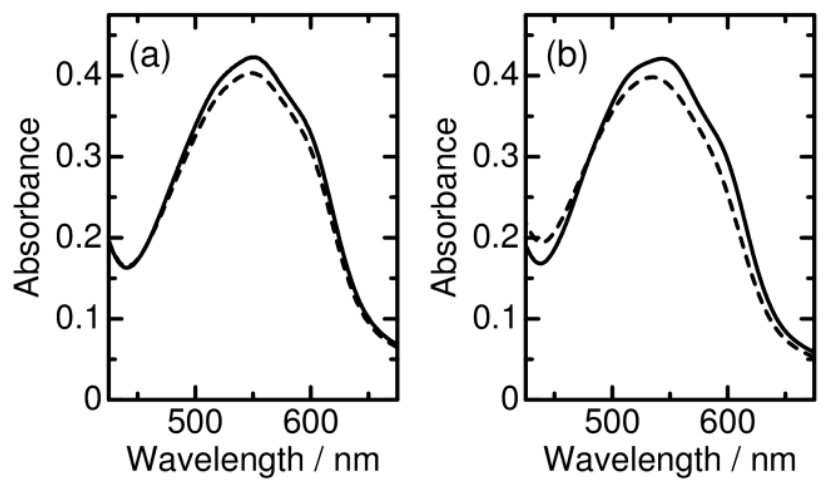

Figure 3. UV-visible absorption spectra of $\mathrm{P} 3 \mathrm{HT} / \mathrm{PF} 12 \mathrm{TBT}$ blend films spin-coated from (a) $\mathrm{CB}$ and (b) $\mathrm{CF}$ solutions. The dashed lines represent data for the as-cast films. The solid lines represent data for the films that were annealed at (a) $80{ }^{\circ} \mathrm{C}$ for $10 \mathrm{~min}$ and at (b) $120{ }^{\circ} \mathrm{C}$ for $10 \mathrm{~min}$, respectively.

3-2. PL Quenching. The $\Phi_{\mathrm{q}}$ of PF12TBT in each blend film was evaluated. As summarized in Table 2, $\Phi_{\mathrm{q}}$ was larger for the CF-blend film than the CB-blend film, independent of the thermal annealing, suggesting that the CB-blend films were likely to form larger phaseseparated structures. After thermal annealing, $\Phi_{\mathrm{q}}$ decreased slightly for both blends, suggesting that each domain grew in size owing to phase separation or ordering of P3HT chains, or both phase separation and ordering of P3HT chains. Thus, $\Phi_{\mathrm{q}}$ of the CF-blend film annealed at $120{ }^{\circ} \mathrm{C}(72 \%)$ was similar to that of the as-cast CB-blend film $(65 \%)$ (see Supporting Information, Figure S4). However, $\Phi_{\mathrm{q}}$ values with this degree of similarity did not always result from a similar blend morphology, as will be discussed below.

3-3. GIWAXS. GIWAXS measurements were performed for the P3HT/PF12TBT blend and neat P3HT films spin-coated from the CF solution. As previously reported, the diffraction peak that appears at approximately $q_{y}=0.39 \AA^{-1}$ can be assigned to the (100) reflection from the alkyl-stacking direction of the P3HT crystallites. ${ }^{24-27}$ Furthermore, the peak at $q_{z}=1.67$ 
$\AA^{-1}$ can be assigned to the (010) reflection along the $\pi$-stacking direction of the P3HT crystallites. ${ }^{24-27}$ The crystal orientation was determined from the azimuthal dependence of the (010) $\pi$-stacking peak intensity. The (010) peak intensity obtained from the two-dimensional GIWAXS image was plotted as a function of the azimuthal angle $(\phi)$ for the as-cast film and films annealed at 80 and $120{ }^{\circ} \mathrm{C}$ for $10 \mathrm{~min}$. All the films exhibited a (010) reflection peak at an angle of $\phi=90^{\circ}$, which corresponds to the scattering vector perpendicular to the substrate plane, indicating that the P3HT crystallites had predominantly "face-on" orientations in the films (see Supporting Information, Figure S5). In terms of the "face-on" crystallite components, the dimensions in the (010) and (100) directions were calculated from the full widths at half maximum of the corresponding Bragg peaks using Scherrer's equation (the shape factor $K$ was assumed to be 0.9$){ }^{28}$ The results are plotted in Figures $4 \mathrm{a}$ and $4 \mathrm{~b}$ as functions of the annealing temperature. After thermal annealing, the P3HT crystallites in the blend film grew in both directions; this behavior is consistent with the increase in $L_{\pi}$ and the decrease in $\Phi_{\mathrm{q}}$ observed for the CF blend films. The crystallite size in the blend film was similar to that in the neat P3HT film following annealing at $120^{\circ} \mathrm{C}$.
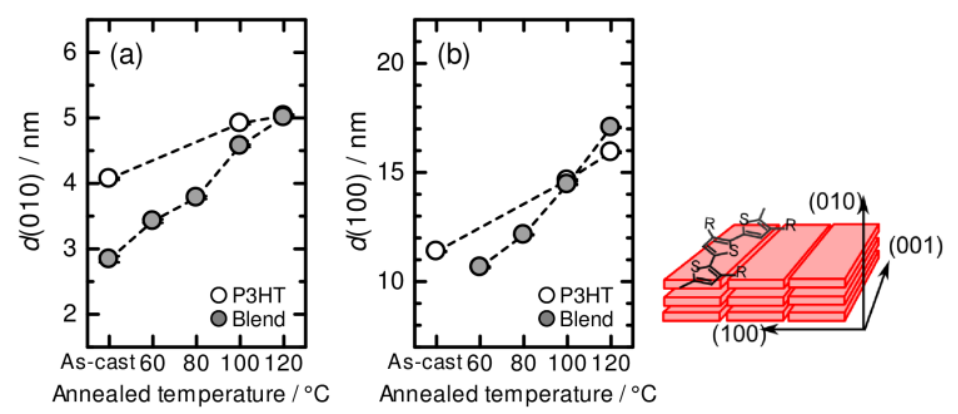

Figure 4. Crystallite dimensions of "face-on" components of P3HT crystallites in the (a) (010) $\pi$-stacking and (b) (100) alkyl-stacking directions as functions of annealing temperature. The solid and open circles represent the results for the P3HT/PF12TBT blend film and neat P3HT film, respectively. The films were spin-coated from CF solutions. 
3-4. Nanoscale Electrical Characterization by C-AFM. Figure 5 shows topographical and current images of the P3HT/PF12TBT blend films, which were prepared under the same conditions as those used for the device fabrication. For the CB-blend films, as shown in Figure 5a, conductive $(I>0 \mathrm{pA})$ and non-conductive $(I=0 \mathrm{pA})$ domains were clearly apparent both before and after thermal annealing, corresponding to topographically lower and higher domains, respectively. As previously reported, ${ }^{14}$ a conductive and topographically lower region can be classified as a P3HT-rich domain, whereas a non-conductive and topographically higher region can be classified as the PF12TBT-rich domain, because our C-AFM setup could selectively detect the hole current from P3HT on the PEDOT:PSS substrate. After thermal annealing at $80{ }^{\circ} \mathrm{C}$, the hole current increased in the P3HT-rich domains; however, no change in the phaseseparated structures was observed in the topographical images. The total hole currents from all pixels in the image were 0.9 and $1.9 \mu \mathrm{A}$ before and after thermal annealing, respectively. The increase in the hole current was primarily observed at the centers of the P3HT-rich domains, whereas no distinct increase was found at the boundary areas close to the PF12TBT-rich domains. These boundary areas can be classified as an intermixed P3HT and PF12TBT region, as will be discussed below. For the CF-blend films, as shown in Figure 5b, the entire observed area showed hole current of as small as a few pA before thermal annealing, but it consisted of highly conductive $(I>\sim 100 \mathrm{pA})$ domains after thermal annealing. There is no clear correlation between the local current and the topographical images. The total hole current from all pixels in the image was $0.1 \mu \mathrm{A}$ before annealing and it increased to $5.9 \mu \mathrm{A}$ after annealing. For comparison, topographical and current images of the neat P3HT films are shown in Figure 6. ${ }^{29}$ The neat films were spin-coated from the CF solution and annealed at 80 and $120^{\circ} \mathrm{C}$; the total currents were as large as 4.9 and $13.9 \mu \mathrm{A}$, respectively. Figure 7(a) 
shows histograms of the current observed at each pixel in the images of the CB-blend films that were as-cast and annealed at $80{ }^{\circ} \mathrm{C}$ for $10 \mathrm{~min}$ (Figure 5a) and in the image of the neat P3HT film annealed at $80{ }^{\circ} \mathrm{C}$ for $10 \mathrm{~min}$ (Figure 6). Figure 7(b) shows histograms of the current observed at each pixel in the images of the CF-blend films that were as-cast and annealed at $120{ }^{\circ} \mathrm{C}$ for $10 \mathrm{~min}$ (Figure 5b) and in the image of the neat P3HT film annealed at $120{ }^{\circ} \mathrm{C}$ for 10 min (Figure 6).

(a) Spin-coated from CB
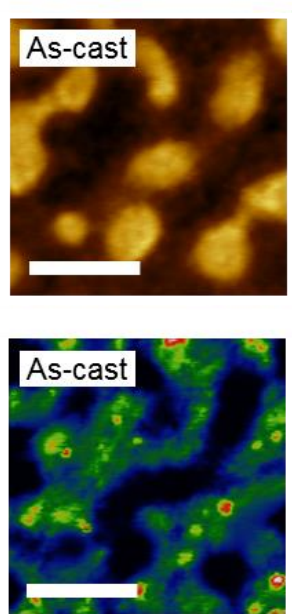

$500 \mathrm{~nm}$

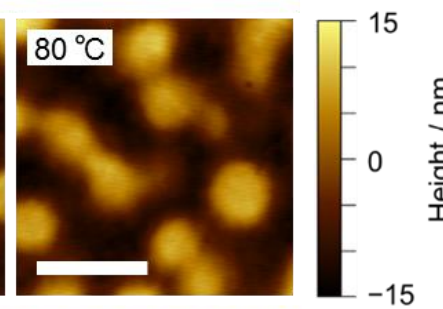

\section{(b) Spin-coated from CF}
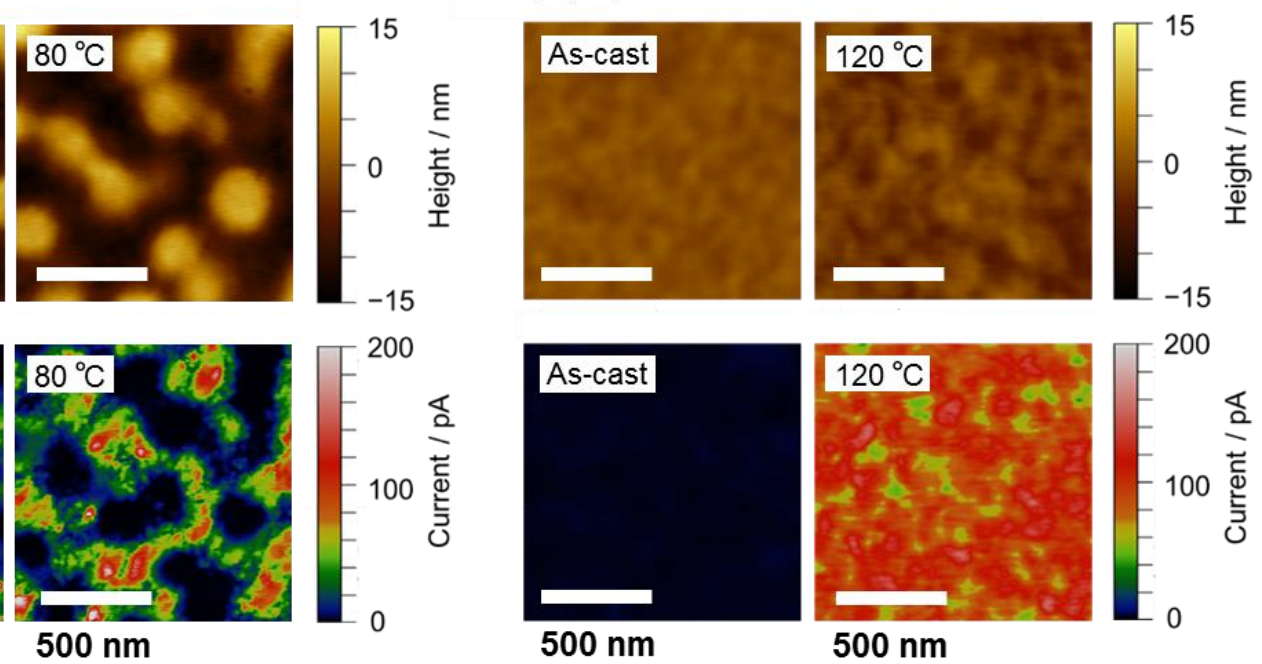

$500 \mathrm{~nm}$

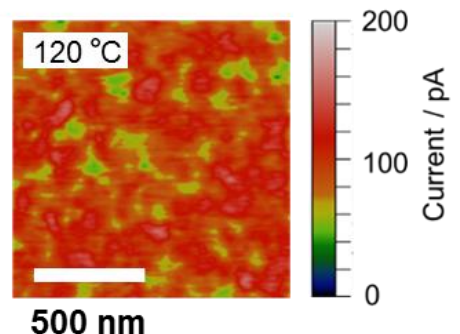

Figure 5. Topographical (top) and hole current (bottom) images $(1.25 \mu \mathrm{m} \times 1.25 \mu \mathrm{m})$ of P3HT/PF12TBT blend films spin-coated from (a) CB solution and annealed at $80{ }^{\circ} \mathrm{C}$ for 10 min, and from (b) CF solution and annealed at $120{ }^{\circ} \mathrm{C}$ for $10 \mathrm{~min}$. 
Neat P3HT spin-coated from CF
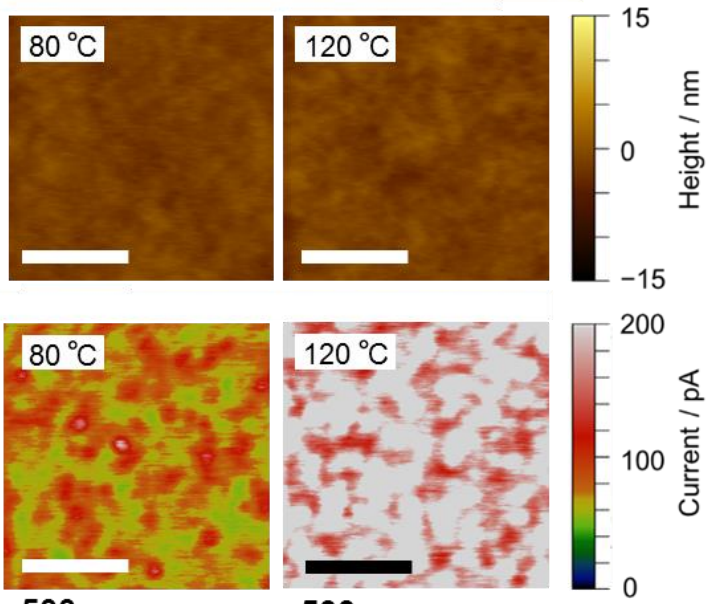

$500 \mathrm{~nm}$ $500 \mathrm{~nm}$

Figure 6. Topographical (top) and hole-current (bottom) images $(1.25 \mu \mathrm{m} \times 1.25 \mu \mathrm{m})$ of neat P3HT films spin-coated from $\mathrm{CF}$ solution and annealed at 80 and $120{ }^{\circ} \mathrm{C}$ for $10 \mathrm{~min}$, respectively.
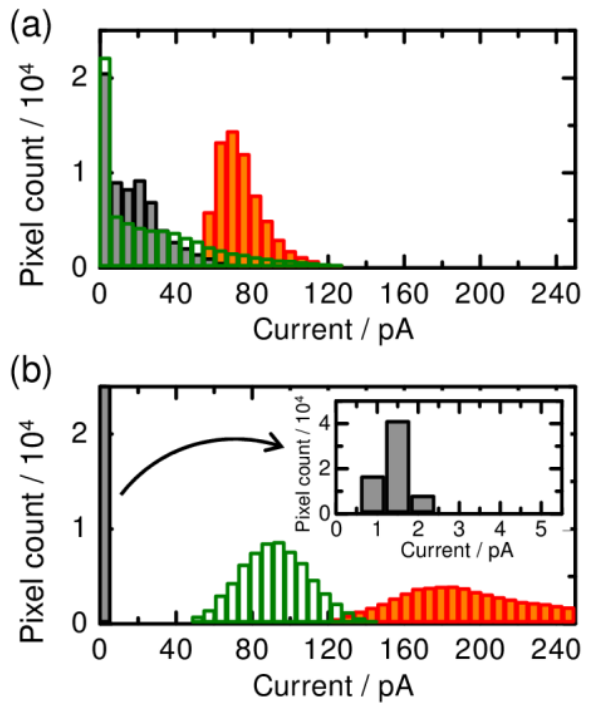

Figure 7. (a) Histograms of the hole current images (Figure 5a and 6) of the blend films that were spin-coated from $\mathrm{CB}$ solution before (black bars) and after thermal annealing at $80{ }^{\circ} \mathrm{C}$ (green bars) and the neat P3HT film from CF solution after thermal annealing at $80{ }^{\circ} \mathrm{C}$ (red bars). (b) Histograms of the hole current images (Figure 5b and 6) of the blend films that were spin-coated from CF solution before (black bars) and after thermal annealing at $120{ }^{\circ} \mathrm{C}$ (green bars) and the neat P3HT film from CF solution after thermal annealing at $120{ }^{\circ} \mathrm{C}$ (red bars). The inset shows the histogram rescaled for the blend film before annealing. 


\section{DISCUSSION}

We first discuss the device performance before thermal annealing in terms of the topographical images of the blend films. As is clear from Figure 5, the choice of spin-coating solvent has a critical impact on the scale of the phase separation in the as-cast blend films. Large domains on the scale of hundreds of nanometers were found in the CB-blend film; however, no distinct phase-separated domain was observed in the CF-blend film. In general, largely phaseseparated domains of donor and acceptor polymers are favorable for charge transport, whereas a finely intermixed domain of donor and acceptor polymers is favorable for charge generation. ${ }^{30}$ Indeed, the CB-blend film was conductive with larger $\sigma$ and $\mu_{\mathrm{h}}$ compared to the CF-blend film. On the other hand, the CF-blend film exhibited a larger $\Phi_{\mathrm{q}}(85 \%)$ than the CB-blend film (65\%). Note that the $\Phi_{\mathrm{q}}$ values provide information on the charge generation efficiency; large $\Phi_{\mathrm{q}}$ value represents efficient charge generation. Therefore, the CB-blend device was expected to exhibit a relatively large FF and small $J_{\mathrm{SC}}$, and the CF-blend device was expected to exhibit a relatively small FF and large $J_{\mathrm{SC}}$. However, this was not the case: both devices exhibited similar $J_{\mathrm{SC}}$ and FF values, and hence, a PCE of less than $1 \%$ before thermal annealing. In summary, the structural differences based on the topographical images are correlated with the macroscopic conductive properties ( $\sigma$ and $\mu_{\mathrm{h}}$ ) and the degree of PL quenching, but they show no clear correlation with the photovoltaic performance.

We next focus on the optimized device performance after thermal annealing. As mentioned earlier, the photovoltaic parameters of the CB-blend and CF-blend devices were improved to different extents after thermal annealing, although negligible changes were found in the topographical images before and after thermal annealing. In other words, there is again no clear correlation between the photovoltaic performance and the topographical images. On the other hand, the bulk-averaged properties such as $\sigma, \mu_{\mathrm{h}}, L_{\pi}$, and $L_{010}$ increased for both devices 
after thermal annealing. This increase is consistent with the increase in the total hole current from all pixels in the C-AFM images. However, the large difference between the optimized photovoltaic performance of the CB-blend and CF-blend devices after the thermal annealing cannot be simply interpreted in terms of the changes in either these bulk-averaged properties or the total current in the C-AFM images. In particular, for the CB-blend device, the increase in $J_{\mathrm{SC}}$ and FF was limited by a factor of $1.1 \sim 1.2$, whereas the $\mu_{\mathrm{h}}$ and C-AFM total hole current increased by a factor of $2.0 \sim 2.1$.

Therefore, we focus on the intermixed region between the P3HT-rich and PF12TBT-rich domains, in which the excitons are more efficiently converted to charge carriers because of the large donor/acceptor interface area. As reported previously, an "intermixed region" is defined as an area with a current less than that observed for the corresponding neat P3HT film. ${ }^{14}$ For the CB-blend films, as shown in Figure 7a, we set the threshold current to $42.7 \mathrm{pA}$ based on the neat P3HT film that was annealed $80{ }^{\circ} \mathrm{C}$. We speculate that these intermixed regions most likely contributed to the photocurrent generation and collection. ${ }^{10}$ On the other hand, the nonconductive regions with a current of $I=0$ were classified as PF12TBT-rich domains, and they contained P3HT as a minor component that did not form a hole-transport network. The conductive regions with a current of $I>42.7$ pA were classified as neat P3HT-like domains, with minor PF12TBT components that did not form an effective electron-transport network. Figure 8 shows current distribution images for the intermixed regions only. As can be seen in Figure $8 \mathrm{a}$, the increase in the hole current in the intermixed regions was modest compared with that observed for the neat P3HT-like domains shown in Figure 5a. The total current in the intermixed regions remained almost constant with values of 0.8 and $0.6 \mu \mathrm{A}$ before and after annealing, respectively, while the total current in the conductive regions increased from 0.9 to $1.9 \mu \mathrm{A}$. In other words, the neat P3HT-like domains were primary contributor to the increase 
in current, which is consistent with the slight increase in $J_{\mathrm{SC}}$ value from 2.0 to $2.4 \mathrm{~mA} \mathrm{~cm}{ }^{-2}$ after annealing. The average current in the intermixed region increased slightly from 20.6 to 23.4 pA after annealing, which represents that the increase in the charge transport efficiency was modest in the intermixed region. This result is also consistent with the small increase in FF (from 0.35 to 0.40 ) after annealing.

(a) Spin-coated from CB

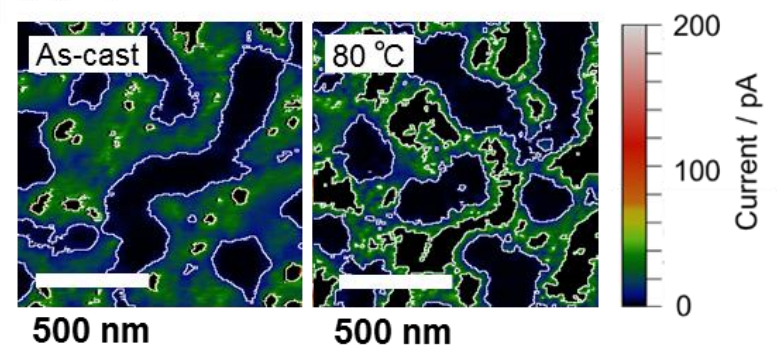

(b) Spin-coated from CF

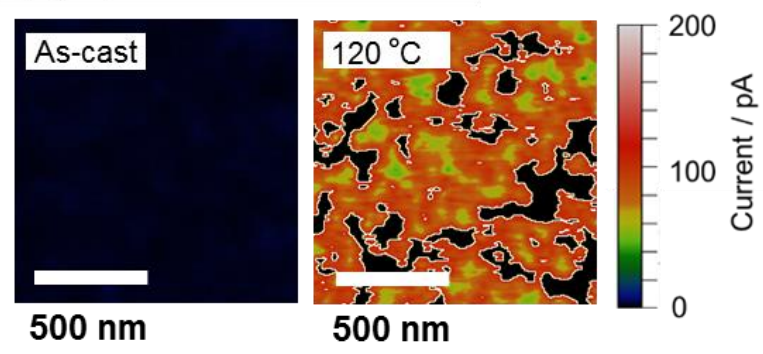

Figure 8. Intermixed region in P3HT/PF12TBT blend films fabricated by spin-coating from (a) $\mathrm{CB}$ solution (as-cast and annealed at $80{ }^{\circ} \mathrm{C}$ for $10 \mathrm{~min}$ ) and (b) $\mathrm{CF}$ solution (as-cast and annealed at $120^{\circ} \mathrm{C}$ for $\left.10 \mathrm{~min}\right)$.

For the CF-blend films, as shown in Figure 7b, we set the threshold current to $103.7 \mathrm{pA}$ based on the neat P3HT film that was annealed at $120^{\circ} \mathrm{C}$. This classified almost the entire observed area as an intermixed region both before and after thermal annealing. Figure $8 \mathrm{~b}$ demonstrates that the increase in the hole current in the intermixed region $(\approx$ the entire area) was significant. The total current in the intermixed region substantially increased after annealing from 0.1 to $4.0 \mu \mathrm{A}$, which is consistent with the significant increase in $J_{\mathrm{SC}}$ from 1.5 to $4.9 \mathrm{~mA} \mathrm{~cm}{ }^{-2}$ after annealing. The average current in the intermixed region was also sharply increased after annealing from 1.30 to $84.2 \mathrm{pA}$, which is also consistent with the marked improvement in FF from 0.29 to 0.55 after annealing. All these findings strongly suggest that good correlation exists between the photovoltaic parameters and the current in the intermixed regions, rather 
than between the former and the total current in the conductive regions or bulk-averaged properties. We therefore conclude that the charge transport properties of the intermixed regions are critical for the device performance of the polymer/polymer blend solar cells.

Finally, we discuss the morphology for efficient charge transport in the optimized CF-blend device that was annealed at $120{ }^{\circ} \mathrm{C}$. The absence of observed non-conductive regions in the current image suggests that the lateral sizes (diameter) of the PF12TBT-rich domains were smaller than the C-AFM resolution $(\sim 20 \mathrm{~nm})$. This is consistent with a domain size of $\sim 15$ $\mathrm{nm}$, which was spectroscopically estimated from the diffusion distance of the PF12TBT excitons. $^{31}$ Furthermore, the UV-vis absorption spectra and GIWAXS measurements suggest that the degree of $\mathrm{P} 3 \mathrm{HT}$ ordering and crystal dimensions in the blend film were similar to those in the neat P3HT film that was annealed at $120^{\circ} \mathrm{C}$. Thus, we assume that P3HT and PF12TBT created efficient charge-transport pathways with a diameter of $<20 \mathrm{~nm}$ (smaller than the CAFM resolution). Consequently, the hole current flowing through the blend film was half of that flowing through the neat P3HT film. In fact, as shown in Figure S6 in Supporting Information, the histogram of the half value of the current measured at each pixel in the image of the neat $\mathrm{P} 3 \mathrm{HT}$ film annealed at $120^{\circ} \mathrm{C}$ is in good agreement with the histogram of the blend film. This indicates that like P3HT in the neat film, nearly all P3HT in the blend film contributed to hole transport. Consequently, the CF-blend device simultaneously attained both high $J_{\mathrm{SC}}$ and high FF, thus exhibiting a maximum PCE of $3.5 \%$.

\section{CONCLUSION}

The morphology-function relationship in P3HT/PF12TBT blend solar cells was studied on the basis of direct C-AFM observations of local charge-transport properties of the nanoscale phaseseparated polymer-blend films. For a blend film prepared by spin-coating from a CB solution, 
coarse phase separation into P3HT-rich and PF12TBT-rich domain structures was observed before and after thermal annealing. The distribution of the local hole conductivity of P3HT suggests that the hole transport was restricted because of the existence of an intermixed region between the P3HT-rich and PF12TBT-rich domains. This blend morphology limited an effective increase in the PCE even after thermal annealing because the majority of the polymer excitons were quenched within the intermixed regions, where hole transport was inefficient. In contrast, for the blend film prepared by spin-caoting from a CF solution, finely mixed blend structures were found throughout the entire the film before and after thermal annealing. The hole transport was not efficient before thermal annealing, but it significantly improved afterwards. In the optimized blend films after thermal annealing, there were phase-separated domain networks with a diameter of less than $20 \mathrm{~nm}$, in which hole transport was as efficient as that in the neat P3HT film. Such an optimized device yielded simultaneously large $J_{\mathrm{SC}}$ and FF, and thus a maximum PCE of 3.5\%. These photovoltaic properties can be explained in terms of the local current in the intermixed region, observed by C-AFM, rather than the topographical features or bulk-averaged properties such as $\sigma, \mu_{\mathrm{h}}, L_{\pi}, L_{010}$, and $\Phi_{\mathrm{q}}$. We thus conclude that the intermixed regions identified from C-AFM observation are most closely related to the charge-generation and charge-collection in polymer/polymer blend solar cells. 


\section{ASSOCIATED CONTENT}

\section{Supporting Information.}

Photovoltaic parameters of CB-blend and CF-blend devices annealed at different temperatures, estimation of $\pi$-conjugation length, PL quenching data, azimuthal profiles, histograms of holecurrent images, and electron mobility of P3HT/PF12TBT blend films.

This material is available free of charge via the Internet at http://pubs.acs.org.

\section{AUTHOR INFORMATION}

\section{Corresponding Author}

*Email benten@ms.naist.jp (H.B.)

\section{ACKNOWLEDGMENTS}

The authors thank Sumitomo Chemical Co., Ltd. for synthesizing and characterizing the acceptor polymer PF12TBT. This work was supported by the JSPS KAKENHI (Grant Number 26288060), the CREST program of the Japan Science and Technology Agency (Grant Number JPMJCR12C4), and the Kansai Research Foundation for technology promotion. SR GISAXS measurements were carried out at the first hutch of the Consortium of Advanced Softmaterial Beamline (FSBL) with the proposal No. 2015A2035, $2015 B 1965$. 


\section{REFERENCES}

(1) Facchetti, A. Polymer Donor-Polymer Acceptor (All-Polymer) Solar Cells. Mater. Today 2013, 16, 123-132.

(2) Benten, H.; Mori, D.; Ohkita, H.; Ito, S. Recent Research Profress of Polymer Donor/Polymer Acceptor Blend Solar Cells. J. Mater. Chem. A 2016, 4, 5340-5365.

(3) Kang, H.; Lee, W.; Oh, J.; Kim, T.; Lee, C.; Kim, B. J. From Fullerene-Polymer to AllPolymer Solar Cells: The Importance of Molecular Packing, Orientation, and Morphology Control. Acc. Chem. Res. 2016, 49, 2424-2434.

(4) McNeill, C. R. Morphology of All-Polymer Solar Cells. Energy Environ. Sci. 2012, 5, 56535667.

(5) Tamai, Y.; Ohkita, H.; Benten, H.; Ito, S. Exciton Diffusion in Conjugated Polymers: From Fundamental Understanding to Improvement in Photovoltaic Conversion Efficiency. J. Phys. Chem. Lett. 2015, 6, 3417-3428.

(6) McNeill, C. R.; Frohne, H.; Holdsworth, J. H.; Dastoor, P. C. Near-Field Scanning Photocurrent Measurements of Polyfluorene Blend Devices: Directly Correlating Morphology with Current Generation. Nano Lett. 2004, 4, 2503-2507.

(7) McNeill, C. R.; Watts, B.; Thomsen, L.; Belcher, W. J.; Greenham, N. C.; Dastoor, P. C.; Ade, H. Evolution of Laterally Phase-Separated Polyfluorene Blend Morphology Studied by X-ray Spectromicroscopy. Macromolecules 2009, 42, 3347-3352.

(8) McNeill, C. R.; Watts, B.; Thomsen, L.; Ade, H.; Greenham, N. C.; Dastoor, P. C. X-ray Microscopy of Photovoltaic Polyfluorene Blends: Relating Nanomorphology to Device Performance. Macromolecules 2007, 40, 3263-2370. 
(9) Swaraj, S.; Wang, C.; Yan, H.; Watts, B.; Lüning, J.; McNeill, C. R.; Ade, H. Nanomorphology of Bulk Heterojunction Photovoltaic Thin Films Probed with Resonant Soft X-ray Scattering. Nano Lett. 2010, 10, 2863-2869.

(10) Snaith, H. J.; Arias, A. C.; Morteani, A. C.; Silva, C.; Friend, R. H. Charge Generation Kinetics and Transport Mechanisms in Blended Polyfluorene Photovoltaic Devices. Nano Lett. 2002, 2, 1353-1357.

(11) Groves, C.; Reid, O. G.; Ginger, D. S. Heterogeneity in Polymer Solar Cells: Local Morphology and Performance in Organic Photovoltaics Studied with Scanning Probe Microscopy. Acc. Chem. Res. 2010, 43, 612-620.

(12) Musumeci, C.; Liscio, A.; Palermo, V.; Samorì, P. Electronic Characterization of Supramolecular Materials at the Nanoscale by Conductive Atomic Force and Kelvin Probe Force Microscopies. Mater. Today 2014, 17, 504-517.

(13) Kondo, Y.; Osaka, M.; Benten, H.; Ohkita, H.; Ito, S. Electron Transport Nanostructure of Conjugated Polymer Films Visualized by Conductive Atomic Force Microscopy. ACS Macro Lett. 2015, 4, 879-885.

(14) Osaka, M.; Benten, H.; Ohkita, H.; Ito, S. Intermixed Donor/Acceptor Region in Conjugated Polymer Blends Visualized by Conductive Atomic Force Microscopy. Macromolecules 2017, 50, 1618-1625.

(15) Coffey, D. C.; Reid, O, G.; Rodovsky, D, B.; Bartholomew, G. P.; Ginger, D. S. Mapping Local Photocurrents in Polymer/Fullerene Solar Cells with Photoconductive Atomic Force Microscopy. Nano Lett. 2007, 7, 738-744.

(16) Mori, D.; Benten, H.; Kosaka, J.; Ohkita, H.; Ito, S.; Miyake, K. Polymer/Polymer Blend Solar Cells with $2.0 \%$ Efficiency Developed by Thermal Purification of Nanoscale-PhaseSeparated Morphology. ACS Appl. Mater. Interfaces 2011, 3, 2924-2927. 
(17) Shen, Y.; Hosseini, A. R.; Wong, M. H.; Malliaras, G. G. How to Make Ohmic Contacts to Organic Semiconductors. ChemPhysChem 2004, 5, 16-25.

(18) Rauscher, M.; Paniago, R.; Metzger, H.; Kovats, Z.; Domke, J.; Peisl, J.; Pfannes, H.-D.; Schulze, J.; Eisele, I. Grazing Incidence Small Angle X-Ray Scattering from Free-Standing Nanostructures. J. Appl. Phys. 1999, 86, 6763-6769.

(19) Clark, J.; Chang, J.-F.; Spano, F. C.; Friend, R. H.; Silva, C. Determining Exciton Bandwidth and Film Microstructure in Polythiophene Films Using Linear Absorption Spectroscopy. Appl. Phys. Lett. 2009, 94, 163306.

(20) Boudouris, B. W.; Ho, V.; Jimison, L. H.; Toney, M. F.; Salleo, A.; Segalman, R. A. RealTime Observation of Poly(3-Alkylthiophene) Crystallization and Correlation with Transient Optoelectronic Properties. Macromolecules 2011, 44, 6653-6658.

(21) Na, J. Y.; Kang, B.; Sin, D. H.; Cho, K.; Park, Y. D. Understanding Solidification of Polythiophene Thin Films during Spin-Coating: Effects of Spin-Coating Time and Processing Additives. Sci. Rep., 2015, 5, 13288.

(22) Pingel, P.; Zen, A.; Abellón, R. D.; Grozema, F. C.; Siebbeles, L. D. A.; Neher, D. Temperature-Resolved Local and Macroscopic Charge Carrier Transport in Thin P3HT Layers. Adv. Funct. Mater. 2010, 20, 2286-2295.

(23) Gierschner, J.; Huang, Y.-S.; Van Averbeke, B.; Cornil, J.; Friend, R. H.; Beljonne, D. Excitonic versus Electronic Couplings in Molecular Assemblies: The Importance of NonNearest Neighbor Interactions. J. Chem. Phys. 2009, 130, 044105.

(24) Kline, R. J.; McGehee, M. D.; Kadnikova, E. N.; Liu, J.; Fréchet, J. M. J.; Toney, M. F. Dependence of Regioregular Poly(3-Hexylthiophene) Film Morphology and Field-Effect Mobility on Molecular Weight. Macromolecules 2005, 38, 3312-3319. 
(25) Kline, R. J.; McGehee, M. D.; Toney, M. F. Highly Oriented Crystals at the Buried Interface in Polythiophene Thin-Film Transistors. Nat. Mater. 2006, 5, 222-228.

(26) Duong, D. T.; Toney, M. F.; Salleo, A. Role of Confinement and Aggregation in Charge Transport in Semicrystalline Polythiophene Thin Films. Phys. Rev. B 2012, 86, 205205.

(27) Sirringhaus, H.; Brown, P. J.; Friend, R. H.; Nielsen, M. M.; Bechgaard, K.; LangeveldVoss, B. M. W.; Spiering, A. J. H.; Janssen, R. A. J.; Meijer, E. W. Microstructure-Mobility Correlation in Self-Organised, Conjugated Polymer Field-Effect Transistors. Synth. Met. 2000, $111-112,129-132$.

(28) Yang, C.; Orfino, F. P.; Holdcroft, S. A Phenomenological Model for Predicting Thermochromism of Regioregular and Nonregioregular Poly(3-Alkylthiophenes). Macromolecules 1996, 29, 6510-6517.

(29) Osaka, M.; Benten, H.; Lee, L.-T.; Ohkita, H.; Ito, S.; Ogawa, H.; Kanaya, T. Nanostructures for Efficient Hole Transport in Poly(3-hexylthiophene) Film: A Study by Conductive Atomic Microscopy. J. Phys. Chem. C 2015, 119, 24307-24314.

(30) Watkins, P. K.; Walker, A. B.; Verschoor, L. B. Dynamical Monte Carlo Modelling of Organic Solar Cells: The Dependence of Internal Quantum Efficiency on Morphology. Nano Lett. 2005, 5, 1814-1818.

(31) Mori, D.; Benten, H.; Ohkita, H.; Ito, S. Morphology-Limited Free Carrier Generation in Donor/Acceptor Polymer Blend Solar Cells Composed of Poly(3-hexylthiophene) and Fluorene-Based Copolymer. Adv. Energy Mater. 2015, 5, 1500304. 
Table of Contents

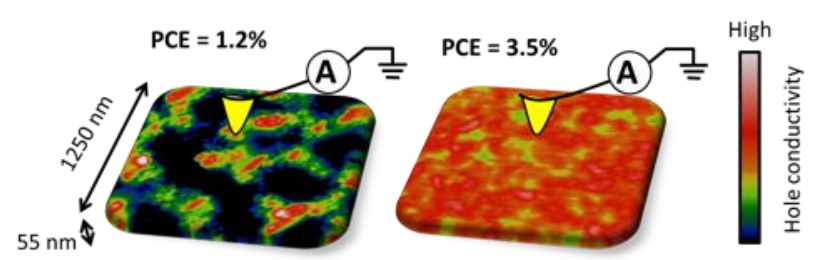

